\title{
Application of Multi-Attribute Value Theory to Improve Cargo Delivery Planning in Disaster Aftermath
}

\author{
Luísa Brandão Cavalcanti, ${ }^{1}$ André Bergsten Mendes, ${ }^{2}$ \\ and Hugo Tsugunobu Yoshida Yoshizaki ${ }^{3}$ \\ ${ }^{1}$ Programa de Engenharia de Sistema Logísticos, Universidade de São Paulo, Av. Prof. Almeida Prado, Travessa 2, No. 128, \\ Cidade Universitaria, 05508-070 Sao Paulo, SP, Brazil \\ ${ }^{2}$ Departamento de Engenharia Naval e Oceânica, Universidade de São Paulo, Av. Professor Mello Moraes, No. 2231, \\ Cidade Universitaria, 05508-030 Sao Paulo, SP, Brazil \\ ${ }^{3}$ Departamento de Engenharia de Produção e Programa de Engenharia de Sistema Logísticos, Universidade de São Paulo, \\ Av. Prof. Almeida Prado, Travessa 2, No. 128, Cidade Universitaria, 05508-070 Sao Paulo, SP, Brazil \\ Correspondence should be addressed to Luísa Brandão Cavalcanti; luisa.cavalcanti@usp.br
}

Received 26 May 2017; Revised 11 August 2017; Accepted 25 September 2017; Published 31 October 2017

Academic Editor: Love Ekenberg

Copyright (C) 2017 Luísa Brandão Cavalcanti et al. This is an open access article distributed under the Creative Commons Attribution License, which permits unrestricted use, distribution, and reproduction in any medium, provided the original work is properly cited.

\begin{abstract}
Although many Operational Research models have been applied to disaster response operations, few researchers aim at revealing Decision Makers' goals or measuring their trade-offs. This article uses a holistic Multi-Criteria Decision Analysis (MCDA) method to elucidate what objectives to pursue and to create appropriate strategies for planning vital items delivery to victims. We propose a framework for applying a Multi-Attribute Value Theory technique and test it with a humanitarian Decision Maker. The resulting mathematical model can be used to evaluate guidelines that make on-field decisions easier, improving (or at least not compromising) their outcomes. Our contribution to the MCDA field includes the documentation of an alternative generation methodology.
\end{abstract}

\section{Introduction}

When a disaster as an earthquake or hurricane strikes, the logistics operations that take place under the principles of humanity, neutrality, and impartiality, aiming to save the victims and helping them to cope with their losses, are called humanitarian logistics [1]. Even though the field also comprises actions to help preventing disasters from happening and to diminish their consequences, the decision explored throughout this paper focuses on the so-called response phase, which begins just after a disaster occurs and before efforts switch to reconstruction and rehabilitation of the affected community [1].

Delivering relief items to disaster victims is one of the most important tasks executed by humanitarian players, such as The Red Cross and Red Crescent Society, when responding to a disaster. Decisions made by those who perform transportation activities include assigning improvised distribution centres to all areas where victims are awaiting for help, deciding what is to be loaded into each available vehicle and designing their routes [2]. The last-mile delivery of cargo is even more complex than it is for traditional logistics, not only due to disruptions of local infrastructure and the typically tense environment of disaster aftermath, but also because demand typically exceeds the delivery capacity, as the available fleet is limited. Moreover, some of the multiple objectives that guide vehicle dispatch decisions are very specific or hard to measure and may conflict with one another. For instance, the distribution ought to be proportionally equal among beneficiaries to avoid tension increase, which is a unique feature of the humanitarian field [3], but, at the same time, Decision Makers aim at delivering as much cargo as possible, which may lead to service level disparities if some victims are harder to reach than others. Furthermore, the traditional balance between level of service and transportation cost is also found in humanitarian operations: 
although the cost is not to be minimized, it may represent a constraint if humanitarian organizations' budgets are low. Recently, to fill the gap of performance measurements specific to the field, Holguín-Veras et al. [4] introduced the concept of deprivation cost, a cost function that reflects victims' suffering from not having a vital item, and how it increases with delay time. Such a function is hard to build and, even though the victims' wellbeing is the fundamental objective of humanitarian operations, there are other factors to be considered, as shown by the value model developed for this research.

The overwhelming context of humanitarian logistics has been acknowledged by the academia, motivating the usage of Operational Research (OR) to tackle different problems faced before and after a disaster occurs [5]. As shown in literature reviews by Altay and Green [6], De La Torre et al. [7], and Holguín-Veras et al. [4], several published mathematical programming models aim at drawing a distribution plan for humanitarian logistics. Such optimization approaches assume objectives of relief distribution are known, as well as their relative importance when more than one objective is considered. Some authors have also attempted to assess trade-offs among humanitarian criteria [8], while others have focused on the development of performance measurements suitable for the field $[4,9,10]$. Yet, the problem-structuring phase has been given little attention by modelers, even though it is argued to be a crucial step for developing better alternatives to solve a problem [11, 12].

Considering both the absence of tools to support dispatch decisions for humanitarian logisticians and the great amount of mathematical programming models that optimize relief distribution, we identified the need of developing appropriate strategies for this task. It seems to be the time to take a step back and perform a decision analysis to elicit the objectives of humanitarian players when distributing goods to disaster victims, since without a model to support their decision, logisticians must rely on mind models, based on nonexplicit assumptions which may not be accurate. Moreover, relationships among the objectives are to be identified and quantified. To accomplish that, we use a combination of problem-structuring and Multiple-Criteria Decision Analysis (MCDA) methodologies to study the problem.

MCDA consists of evaluating alternatives to a given decision against upon a set of performance criteria, to improve decision-making [13]. That is, to carry on a MCDA one must know, to the very least, the decision to be made, its alternative solutions, and relevant evaluation criteria for choosing the best alternative. Controversially, MCDA methodologies do not cover all steps for defining these three aspects of decisionmaking, perhaps because problem-structuring had not been given much attention until recently. In fact, in a recent literature review [14], problem-structuring methods are separated from MCDA methodologies, although the authors mention a few holistic methodologies, like Keeney's [11] Value-Focused Thinking (VFT) approach.

According to VFT, a decision opportunity should be tackled by focusing on Decision Makers' goals that can be directly or indirectly fulfilled by decision outcomes [16].
Hence, VFT takes a different starting point than alternativefocused thinking, which considers possible alternatives in the early stages of modeling (as do MCDA outranking methods, e.g.) [17]. As a result, Keeney's method leads to the identification of more alternatives and better performance criteria than alternative-focused thinking. This is especially important for decisions such as policy/strategy designing, for which the identification of alternatives is not a straightforward task (as opposed to choosing a supplier, e.g.). However, VFT is generic in the sense that it does not specify how alternatives should be scored against the criteria, nor does it specify a way to aggregate these partial scores. Hence, it is necessary to combine VFT with a MCDA technique. Within the existing MCDA techniques, those of value measurement are specially suited for Keeney's [11] Value-Focused Thinking (VFT) approach, as pointed out elsewhere [17].

In general, an application of value measurement methodologies follows the steps of (1) identification of decision opportunity; (2) elicitation of objectives; (3) definition of criteria; (4) formulation of alternatives; (5) scoring alternatives against each criterion; (6) assessment of criteria weights; (7) aggregation of results; and (8) analyzing results [13, 15]. The first four stages comprise the problem-structuring phase, which must be wisely carried out, as inconsistencies between Decision Makers' values and the model structure undermine the quality of its results. Nonetheless, although unwell structured models restrain the creation of new, better alternatives for a decision $[11,12,16,18]$, many authors treat decision opportunities as given problems associated with known performance criteria, not paying enough attention to problem-structuring $[19,20]$.

In this paper, a Multi-Attribute Value Theory (MAVT) methodology is applied with VFT to elucidate the objectives of delivering cargo to disaster victims during response operations, create solution alternatives, and evaluate them. Because of the nature of the problem studied here, alternatives turned out to be policies that could be used to expedite aid delivery planning in disaster aftermath, so it was necessary to use a specific technique for designing such policies, namely, the Strategy Generation Table and Analysis of Interconnected Areas (AIDA). As MAVT uses partial value functions to measure the level of accomplishment of each relevant performance criterion, it must be followed by a ranking method to aggregate these partial results. For this purpose, we build a Simple Multi-Attribute Rating Technique with Exploiting Ranks (SMARTER) model, which burdens the Decision Maker (DM) with less cognitive weight than other MAVT methods, without compromising the solution quality $[21,22]$.

MAVT has been applied before [23] to a different humanitarian logistics problem (site location) and with Preference Ranking Organization Method for Enriching Evaluations II instead of SMARTER - we chose SMARTER because it could be easily adapted for use via online questionnaires. Those authors, however, used international standards for risk and vulnerability assessments as evaluation criteria, instead of consulting with real Decision Makers. Also, as done elsewhere [20, 24], we used the literature to complement the DM's view on the problem. Other MCDA methods have 
been recently applied to facility-location decisions faced by humanitarian logisticians, as the hybrid AHP-based heuristic presented in the works of $[20,24,25]$, without documenting the processes used for alternative generation and criteria definition. As far as MCDA methodologies go, to the authors' knowledge this is the first work to combine VFT with SMARTER and AIDA and, most importantly, to cover all phases of MCDA (see, e.g., literature reviews $[14,17,26]$ ). Hence, our contribution to the MCDA literature is twofold: we expand the MAVT's applicable fields, as to the best of our knowledge no earlier application to aid distribution has been made; and we propose a combination of problem-structuring and MCDA techniques that are especially suited for policy designing problems, covering all phases of MCDA modeling. It is not within the scope of this work to compare the methodologies chosen here with other existing MCDA techniques, but to propose a combination that can be successfully used for strategic decision problems, such as policy designing. As different methodologies give different emphasis to each modeling step [14], choosing a suitable MCDA method (or a combination of methods) may be challenging.

The article is organized as follows: in Section 2, the methodology used in this work is presented; Section 3 presents the results of applying SMARTER to the aid delivery problem; and, in Section 4, final remarks are given.

\section{Methodology}

Before explaining how each step of MCDA was carried out in this research, it is important to state how the interactions between the contact-author of this paper and the DM happened. In fact, the author played two roles during the modeling process: as an interviewer, she interacted with the DM through one meeting and four online surveys, enabled by Survey Monkey and Survey Gizmo online platforms; as a modeler, the author translated all the information provided by the DM into a computational language, using the software VISA version 8.1 for Windows. Two parallel environments may be defined to illustrate the dynamic of model-building tasks, one characterized by discussions and brainstorming guided by the interviewer, employing a Value-Focused Thinking approach, and another comprising the modeling process itself, which followed the SMARTER methodology. Figure 1 illustrates both environments, representing the author at their intersection.

The MCDA process used here is divided into three modeling phases, presented next, following Franco and Montibeller's [15] framework for MCDA methodologies. For this work, as there was limited access to real Decision Makers, we used information available at humanitarian organizations' websites and from academic literature to complement the DM's views and enrich brainstorming steps. The DM consulted is a former Brazilian Captain who worked on the United Nations Stabilization Mission in Haiti, MINUS$\mathrm{TAH}$, before and after the 2010 earthquakes, serving the Brazilian military peacemaking troop. At that occasion, few humanitarian organizations had the resources to work independently, so a scarce fleet was shared among them. To coordinate such a system, all decisions were made by the Joint
Operations and Tasking Centre (JOTC), a committee formed by representatives from the MINUSTAH and the UN's Office for the Coordination of Humanitarian Affairs (OCHA). As a coordinator's point of view was desired for this work, the DM was asked to use his experience with the JOTC to support his inputs on all modeling phases.

In the first modeling phase, the problem (or decision opportunity) to be analyzed is defined. Before contacting the DM, the authors of this paper executed a literature review on academic and nonacademic material, to consolidate important concepts of humanitarian operations. Afterwards, the interviewer asked the DM about groups and organizations that could affect or be affected by the decision problem under analysis, which led to the identification of stakeholders and the definition of an explicit point of view for making decisions. Then, the stakeholders were classified using a power versus interest chart shown in Section 3.1.

The second phase comprises all steps necessary to structure the mathematical decision-making model. A first step is to elucidate the DM's objectives, using brainstorming techniques and a mind mapping tool, which here was the software XMind. To enrich the discussion, first the DM was asked to enumerate all objectives that he would consider when drawing a distribution plan. Then, the interviewer showed him the objectives found in the literature and asked him to review the original objectives list. Finally, the DM was asked to explain, for each objective, why he would consider it and what would be the direct consequences of it, which led to the enumeration of more objectives and the identification of relationships between pairs of objectives. From the network built, which depicts mean-objectives and end-objectives, the modeler built a value tree.

Once the value tree was developed, the DM answered a set of questions that confirmed every low-end objective (leaves of the tree) could be interpreted as a performance criterion to evaluate a distribution plan. Then, for each performance criterion an attribute was selected by the DM, also via questionnaire, allowing the measurement of alternatives' performance levels in terms of that criterion. In addition, the scale of each attribute was defined by assigning references to the extreme values that could result from a hypothetical distribution of aid: the worst performance in terms of a criterion that would still be acceptable assumes one end of the scale, which is assigned to a value of zero, whereas the best achievable performance in terms of the same criterion occupies the other end of the scale, to which the value 100 is assigned. As in [27], it is assumed that the value function associated with the scale of each attribute, called partial value function, is linearly increasing.

At the end of the second phase, possible solutions to the problem (usually referred to as alternatives) are elaborated. To create a set of alternatives, we followed a VFT approach [16]: first, we tried to come up with alternatives that would fulfill one performance criterion at a time, then two at the same time, and so on, until the number of criteria considered made it impossible to come up with solutions that would succeed in all of them. Since the alternatives actually represent strategies for developing a distribution plan, we also used Howard's [28] Strategy Generation Table and a technique 


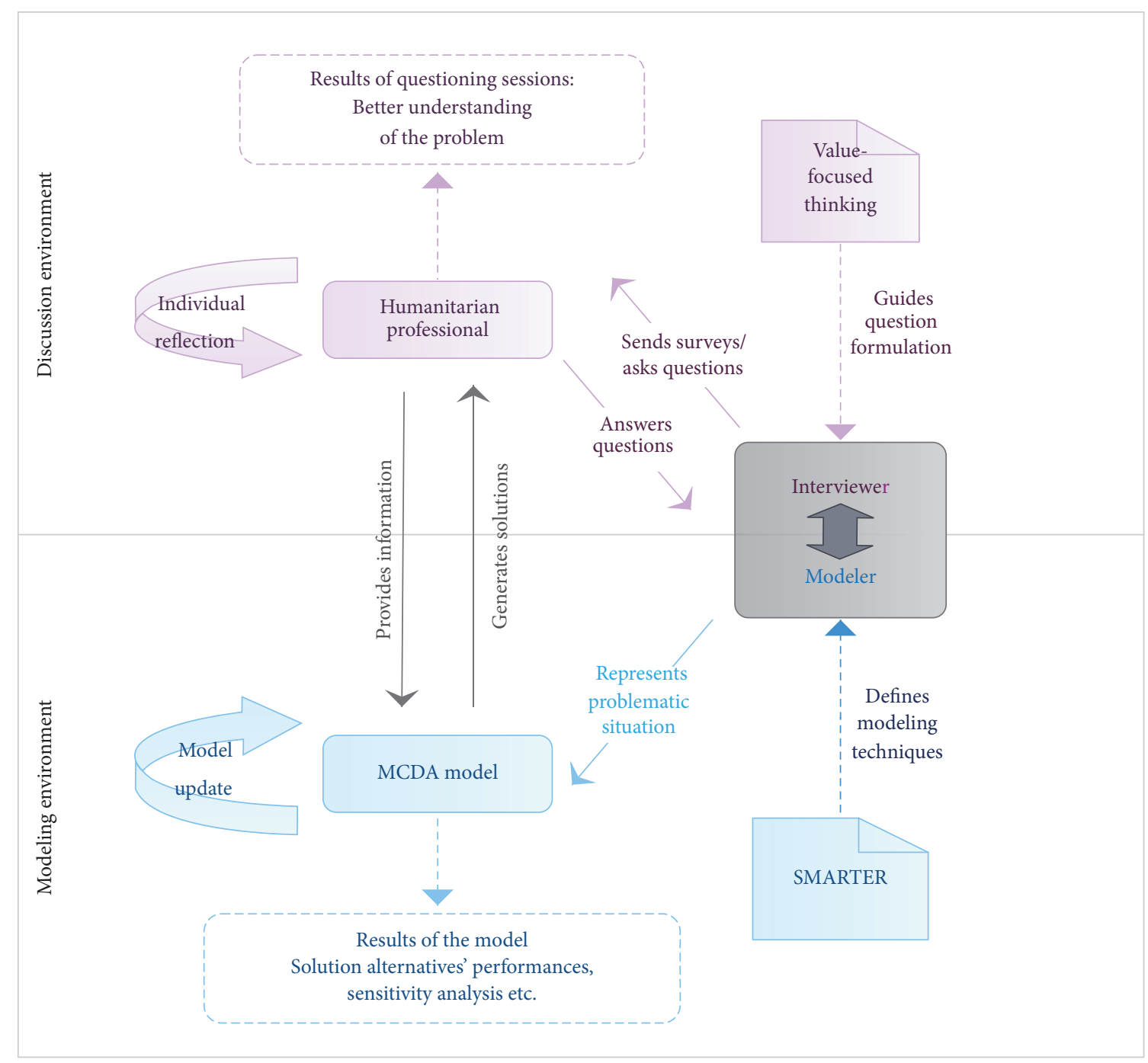

FIGURE 1: Discussion and modeling environments, showing the author's roles as interviewer and modeler.

called Analysis of Interconnected Decision Areas (AIDA) [29] to create possible strategies. These techniques start from the division of a strategy into a set of small decisions, each set representing a decision area. In turn, each area is composed of a list of options describing alternatives to the area-specific decision. The designation of decision areas and their options were done during the process of thinking how each objective of the value tree could be achieved, by identifying common aspects of the alternatives that we could think of. General aspects of each alternative were defined as decision areas, such as the order by which the cargo movement requests would be delivered, and more specific aspects became the options within each decision area, for instance, a FIFO rule to sort the cargo movement requests. Once all options and areas were included in the strategy generation table, we made pairwise checks for each combination of options from different decision areas to see if they could be used together or not. Assembling a strategy, then, was done by simply combining only the compatible options from different areas of the decision; that is, AIDA was used to remove from the set of possible combinations those that do not make sense.

The third and last phase of SMARTER comprises preference modeling and evaluation of alternatives, which in this case are strategies for planning aid delivery to disaster victims. For each criterion of the value tree, the alternatives were placed by the DM directly along the attribute scale, according to their expected performance in the corresponding criterion. This resulted in the partial performances of every strategy in terms of each evaluation criterion, but the relative importance of each criterion was still undefined. Next, the DM was asked to sort the criteria according to the relative importance of going from the worst to the best level of their corresponding attributes, resulting in a criteria ranking list. Then, using the Order of Centroid formula (ROC) [21], each rank position was transformed into a number that represents the weight associated with the criterion of that position. Finally, the 
TABLE 1: Steps followed for building and applying the decision model presented here. Each step includes the identification of its modeling phase (according to [15]) and the specific problem-structuring and/or MCDA methodologies used.

\begin{tabular}{|c|c|c|}
\hline Interaction with DM & MCDA phase & $\begin{array}{l}\text { Problem- } \\
\text { structuring/MCDA } \\
\text { methodologies }\end{array}$ \\
\hline $\begin{array}{l}\text { Survey } 1 \\
\text { (preparatory) }\end{array}$ & $\begin{array}{l}\text { PHASE 1: problem-structuring: } \\
\text { (i) Definition of the decision to be made and point of view adopted } \\
\text { (ii) Brainstorming on objectives }\end{array}$ & $\begin{array}{l}\text { VFT } \\
\text { Stakeholder analysis }\end{array}$ \\
\hline Live meeting & $\begin{array}{l}\text { PHASE 2: design of mathematical MCDA model: } \\
\text { (i) Elicitation of objectives } \\
\text { (ii) Identification of causal relationships between pairs of objectives, building a } \\
\text { network of means-ends objectives }\end{array}$ & $\begin{array}{l}\text { VFT (map of means-ends } \\
\text { objectives) }\end{array}$ \\
\hline- & $\begin{array}{l}\text { PHASE 2: design of mathematical MCDA model: } \\
\text { (i) Creation of value-tree from the means-ends network of objectives. }\end{array}$ & VFT \\
\hline Survey 2 & $\begin{array}{l}\text { PHASE } 2 \text {-Design of mathematical MCDA model: } \\
\text { (i) Proposition of value tree built from the means-ends network of objectives } \\
\text { (ii) Value-tree's properties check }\end{array}$ & $\begin{array}{l}\text { VFT } \\
\text { MAVT }\end{array}$ \\
\hline Survey 3 & $\begin{array}{l}\text { PHASE 2: design of mathematical MCDA model: } \\
\text { (i) Validation of final value tree, confirming all value tree properties are valid } \\
\text { (ii) Definition of an attribute for each low-end objective } \\
\text { (iii) Definition of attributes' scales }\end{array}$ & $\begin{array}{l}\text { VFT } \\
\text { MAVT }\end{array}$ \\
\hline - & $\begin{array}{l}\text { PHASE 2: design of mathematical MCDA model: } \\
\text { (i) Creation of alternatives to the decision } \\
\text { (ii) Creation of model using a MCDA software (VISA) }\end{array}$ & $\begin{array}{l}\text { VFT } \\
\text { Strategy Generation Table } \\
\text { and AIDA }\end{array}$ \\
\hline Survey 4 & $\begin{array}{l}\text { PHASE 3: preference modelling \& alternative evaluation: } \\
\text { (i) Alternative scoring against each objective and criteria ranking }\end{array}$ & SMARTER \\
\hline- & $\begin{array}{l}\text { PHASE 3: preference modelling \& alternative evaluation: } \\
\text { (i) Compilation of results and sensitivity analysis }\end{array}$ & SMARTER \\
\hline
\end{tabular}

overall performance of each strategy was calculated as the weighted sum of their partial results, and best alternative was selected.

Table 1 presents, in a chronological order, all steps executed for building the MCDA model presented in this paper. MCDA or problem-structuring methodologies used in each step are also shown. Steps with no interaction with the DM (marked with "-_" in the first column of Table 1) were carried out by the modeler alone.

\section{Application of the Proposed Framework to a Humanitarian Logistics Problem}

Next, an application of our framework is documented, divided into the three modeling phases described above. Prior to the beginning of the modeling process, the DM is asked to take a standpoint, and to answer all questions according to it. The DM chose to take a coordinator standpoint, based on his experience in Haiti, when the Brazilian Army acted together with other humanitarian actors to reach out to the victims. Thus, the resulting model reflects his interpretation of the Brazilian Army's values under such a scenario.

This standing point is consistent with the United Nations' (UN) Logistics Cluster, an umbrella method designed to tackle the challenge of performing an effective and efficient aid distribution in disaster response operations. This cluster approach consists of naming a leader organization to coordinate transportation of goods and performing lastmile delivery of cargo on behalf of the humanitarian community, using shared vehicles and facilities. A coordinator may be chosen naturally when the leader emerges through interactions among humanitarian organizations; otherwise the cluster is activated with the World Food Programme (WFP) as its leader [30]. Nevertheless, the efforts of all organizations are combined to achieve a good result, which may happen without the UN's Logistics Cluster whenever there is collaboration and coordination among humanitarian players. The good functioning of a coordinated logistics unit may not rely solely on diminishing victims' suffering, as suggested by Holguín-Veras et al. [4], but also on managing a heterogeneous group of stakeholders. Taking a coordinator's point of view, we look at the decision from a different perspective than the one of a humanitarian player, without neglecting its goals.

3.1. Phase 1: Problem-Structuring. The decision context was defined by the interviewer in a preparatory survey as follows: "imagine that shortly after a disaster, you are in charge of coordinating the delivery of items to victims. In this scenario, you do not have information about the conditions of the victims, although you know that some regions are harder hit than others. It was a great disaster, so there is a lot of cargo being shipped from all over the world, accumulating at available entry points of the country, but your capacity to 


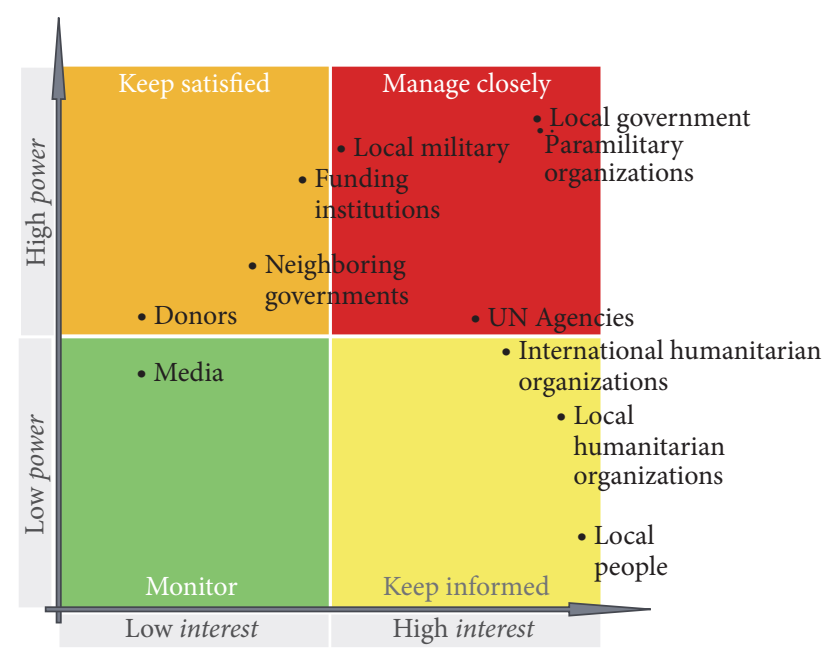

FIGURE 2: Power versus Interest grid showing all stakeholders identified by the Decision Maker.

deliver these items is limited. A relief distribution plan needs to be drawn, designating vehicles to demand points, where victims receive help, and deciding which loads will be carried by each vehicle. Such a plan should comprise a time horizon of one week."

All questions asked in this first survey followed Keeney's [12] recommendations for constructing a value-based model. For example, the practitioner was asked what features of a relief distribution are considered negative, with the intention of making him think about the objectives that are unmet when the outcomes of a humanitarian action manifest such bad characteristics. Then, the DM enumerated six objectives that he considered relevant for the elaboration of a distribution plan. Afterwards, 20 objectives identified in the literature were presented to the DM, who validated 11 of them, of which only 3 had already been listed in the previous step.

Once the decision context decision was clearly stated, stakeholders were identified. In the initial minutes of the meeting with the DM, he was questioned about the organizations and groups that would be interested in the distribution plan of the problem portrayed and how they relate to each other in terms of power to influence the decisions to be made, and in level of interest in the aid distribution outcomes. Victims, donors, governments, local communities, neighboring governments, humanitarian organizations, military corps with ongoing operations in the region, local paramilitary organizations, UN operational agencies (such as the WFP), and international development institutions were cited by the DM. After naming all stakeholders, the DM was asked to place them on a power-interest grid, presented in Figure 2, beginning with the stakeholder of highest power and interest in the outcomes of an aid distribution. In this case, "Local government" was first positioned in the top corner of the grid; then one-by-one the stakeholders were added to the grid, by comparing them with one another and repositioning them when necessary.

By building such a grid, the DM is nudged to consider the interests of players that can interfere with the distribution plan, especially powerful stakeholders. In the present work, the interviewer made sure to ask if victims, local governments (or the organization in charge of naming priorities), and the humanitarian community were considered throughout the value model, although they do not represent the point of view adopted.

3.2. Phase 2: Model Structuring. During the brainstorming meeting, the objective network showed in Figure 3 was developed. The interviewer started by adding to the screen all objectives defined by the DM in the preliminary survey. Then, for each item, "what for" and "why" questions were asked to the DM, whose answers were also added to the network, connected to the original objective. Hence, each connection of the resulting network represents a causal relationship between a pair of goals. Such process was repeated until the DM could not add new objectives to the items already depicted in the network. Interestingly, the DM refused to add budget constraints to the list of objectives, arguing that during the first phase of disaster response there would be no concern about the budget. This may indicate a discrepancy between existing OR models and DM's values, which may be confirmed in future studies, by including more DMs that represent other stakeholders identified here.

After the meeting, an initial version of the value tree was built by the modeler, based on the developed network, and sent to the DM along with an online questionnaire for its validation, in the second survey. Then, in the third survey answered by the DM, the interviewer asked a set of questions to confirm that the tree contains only elements that are essential to the decision-making process, and that it is intelligible, operational, and nonredundant. Finishing the third survey, all attributes and their scales were defined. Figure 4 shows the final value tree.

The tree presented contains two delimited areas, tagged as "context of initial disaster response: military supporting humanitarian operations" and "context of planning aid delivery during the first week of response operations," describing possible decision contexts related to first week of response operations," describing possible decision contexts related to humanitarian operations. This way, we emphasize to the DM that the decision opportunity studied is that of planning aid delivery during the first week of response operations, assuming the military is supporting humanitarian operations. The value tree is presented by connected rectangle shapes, while attributes appear in oval shapes with their scales to the right, at the lowest level of the tree. It can be noted that the tree has one top-level fundamental objective (to "perform transportation of supplies to victims (...)") and five low-level objectives, usually referred to as the leaves of the value tree ("use safe routes," "promote stability (...)," etc.). Extreme levels of each attribute appear with the highest, best achievable level on top of the lowest acceptable level. For the objectives "reach victims fast enough (...)" and "to prioritize the more severely hit regions" we opted for local scales, which means the worse level of the corresponding attribute corresponds to the performance of the worst alternative while the better level reflects the best alternative. 


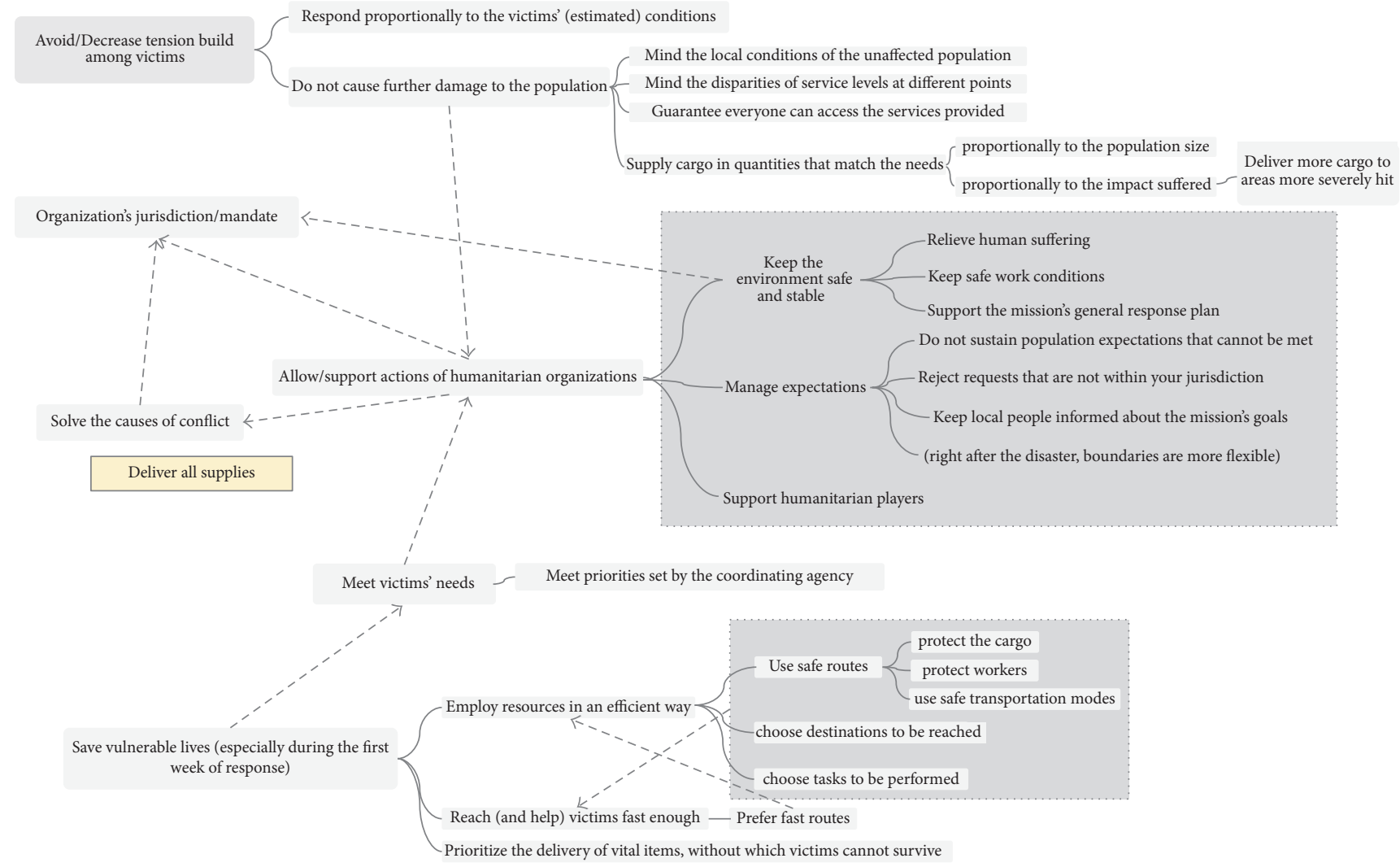

FIGURE 3: Network of Objectives developed during the brainstorming session, in which a connection between a pair of elements represents a causal relationship between objectives.

TAble 2: Strategy Generation Table used for creating strategies for drawing an aid distribution plan in disaster aftermath.

\begin{tabular}{|c|c|c|c|c|c|}
\hline \multicolumn{6}{|c|}{ Decision areas } \\
\hline \multicolumn{2}{|r|}{ A: Cargo type } & \multicolumn{2}{|r|}{ B: Request selection } & \multicolumn{2}{|c|}{ C: Fleet configuration } \\
\hline$\#$ & Description & $\#$ & Description & $\#$ & Description \\
\hline $\mathrm{A}_{1}$ & $\begin{array}{l}\text { Send a predetermined mix } \\
\text { of products }\end{array}$ & $\mathrm{B}_{1}$ & $\begin{array}{c}\text { Select requests accordingly to their } \\
\text { destinations, prioritizing points that are } \\
\text { faster to reach }\end{array}$ & $\mathrm{C}_{1}$ & $\begin{array}{l}\text { Allow vehicles to travel } \\
\text { independently, not } \\
\text { enforcing convoys }\end{array}$ \\
\hline $\mathrm{A}_{2}$ & $\begin{array}{l}\text { As specified by cargo } \\
\text { movement requests }\end{array}$ & $\mathrm{B}_{2}$ & $\begin{array}{l}\text { Select requests accordingly to their cargo, } \\
\text { prioritizing urgent needs }\end{array}$ & $\mathrm{C}_{2}$ & Always travel in convoys \\
\hline \multirow[t]{3}{*}{$\mathrm{A}_{3}$} & $\begin{array}{l}\text { Select the highest priority } \\
\text { cargo available }\end{array}$ & $\mathrm{B}_{3}$ & $\begin{array}{l}\text { Select requests accordingly to the priority } \\
\text { level of their destinations }\end{array}$ & & \\
\hline & & $\mathrm{B}_{4}$ & $\begin{array}{l}\text { Select requests accordingly to their } \\
\text { destinations, first to satisfy powerful local } \\
\text { groups, then by priority levels }\end{array}$ & & \\
\hline & & $\mathrm{B}_{5}$ & $\begin{array}{l}\text { Select requests accordingly to their issue } \\
\text { date, following a First In-First Out rule } \\
\text { (FIFO) }\end{array}$ & & \\
\hline
\end{tabular}

To design solution alternatives, the modeler identified three decision areas that together form a possible solution to the problem: the choice of loads to be transported by each vehicle; the order by which cargo handling requests issued by humanitarian organizations are selected; and the configuration of the fleet that specifies whether convoys will be used or not. To come up with this set of decision areas, the modeler brainstormed on guidelines that could be followed to make dispatch decisions easier and that are sufficient to draw a distribution plan. As there are several ways of addressing each decision area, each area comprises a set of options, as can be seen in Table 2. For instance, if the coordinator wants to prioritize regions where victims are in worse conditions, movement requests that are addressed to such places will be 


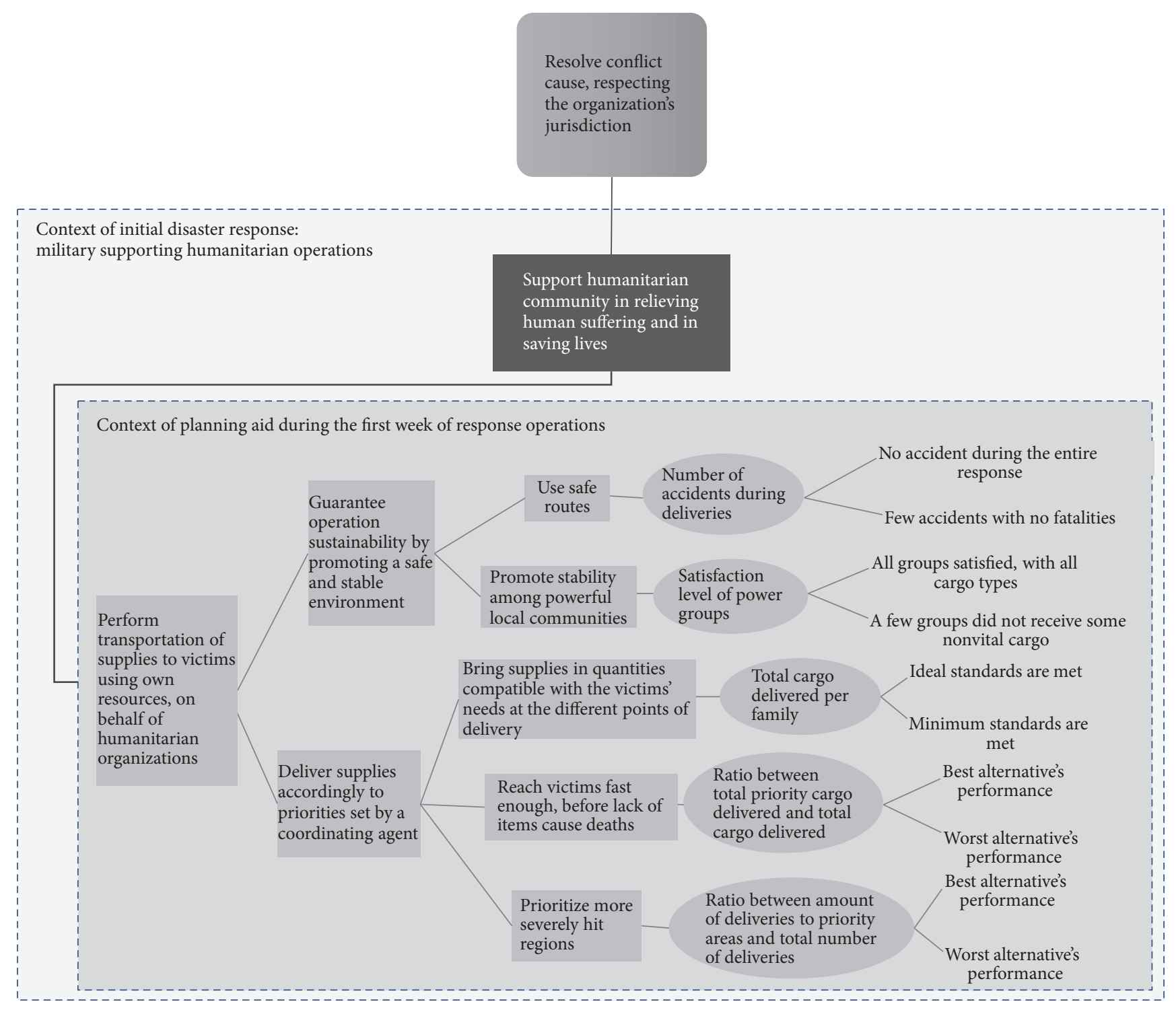

FIGURE 4: Value tree used for creating and evaluating alternatives to the decision studied: oval-shaped elements are attributes and underlined elements are top and bottom levels of an attribute's scale.

selected first, until a minimum service level is accomplished (option $\mathrm{B}_{3}$ of Table 2). On the other hand, it is possible that the coordinator needs to assure certain kind(s) of cargo are delivered to all affected regions as soon as possible, so movement requests may be chosen according to the products they contain, as described by option $\mathrm{B}_{2}$. It can be noted that both strategies describe a way to sort the movement requests using a certain characteristic of them, and each option reflects an objective found in the value tree. Also, the 2 strategies mentioned guide the same aspect of the decision and therefore cannot be used simultaneously, so they belong to the same decision area B.

It is worth mentioning that another possible decision area not added to the problem is the order by which vehicles are assigned to loads, in case a heterogeneous fleet is available. Such decision was intentionally left out of this work, assuming a homogeneous fleet, to simplify the strategies considered by the DM. Since the greater the number of elements describing a solution alternative, the greater the burden put on the $\mathrm{DM}$, it is important that the interviewer balances the value gained by adding a new dimension to the table against the increase in the difficulty of evaluating or understanding the alternatives due to their detail level. As this balance may be hard to measure, the alternative generation may be done in several interactions until the modeler and the DM are both comfortable with the resulting alternative set. For instance, if in this example the modeler or the DM felt it was important to add to the table the allocation order of vehicles to loads, 
TABLE 3: Application of Analysis of Interconnected Decision Areas (AIDA) to the strategy table: the grid represents pairwise comparisons between options of 2 different decision areas, with " $\mathrm{C}$ " denoting compatible options and "I" incompatible.

\begin{tabular}{ccccccccc}
\hline & & & & $\mathrm{B}$ & & & \multicolumn{2}{c}{$\mathrm{C}$} \\
& & $\mathrm{B}_{1}$ & $\mathrm{~B}_{2}$ & $\mathrm{~B}_{3}$ & $\mathrm{~B}_{4}$ & $\mathrm{~B}_{5}$ & $\mathrm{C}_{1}$ & $\mathrm{C}_{2}$ \\
\hline & $\mathrm{A}_{1}$ & $\mathrm{C}$ & $\mathrm{I}$ & $\mathrm{C}$ & $\mathrm{C}$ & $\mathrm{I}$ & $\mathrm{C}$ & $\mathrm{C}$ \\
$\mathrm{A}$ & $\mathrm{A}_{2}$ & $\mathrm{C}$ & $\mathrm{C}$ & $\mathrm{C}$ & $\mathrm{C}$ & $\mathrm{C}$ & $\mathrm{C}$ & $\mathrm{C}$ \\
& $\mathrm{A}_{3}$ & $\mathrm{C}$ & $\mathrm{C}$ & $\mathrm{C}$ & $\mathrm{C}$ & $\mathrm{C}$ & $\mathrm{C}$ & $\mathrm{C}$ \\
\hline & $\mathrm{B}_{1}$ & & & & & & $\mathrm{C}$ & $\mathrm{I}$ \\
& $\mathrm{B}_{2}$ & & & & & & $\mathrm{C}$ & $\mathrm{I}$ \\
$\mathrm{B}$ & $\mathrm{B}_{3}$ & & & & & & $\mathrm{C}$ & $\mathrm{C}$ \\
& $\mathrm{B}_{4}$ & & & & & & $\mathrm{C}$ & $\mathrm{C}$ \\
& $\mathrm{B}_{5}$ & & & & & & $\mathrm{C}$ & $\mathrm{I}$ \\
\hline
\end{tabular}

it could have been done in a second round of alternative creation and evaluation, so that the first contact of the DM with the method was simpler.

Once a strategy table has been developed, it is easy to design different strategies (that represent solution alternatives to our problem): we simply combine an option from each of the three columns of the grid. However, some pairs of options may not be combined because they conflict with each other; for example, it does not make sense to assemble a predetermined mix of products $\left(A_{1}\right)$ and select requests according to product priority $\left(B_{2}\right)$, because in that case cargo of different organizations will be combined, so the only question left when $A_{1}$ applies is how to choose between movement requests that contain cargo of the same type. Hence, the Analysis of Interconnected Areas was used to reduce the set of possible combinations, restricting it only to the viable options. This technique consists of questioning, for every pair of elements from different decision areas, if the elements can be used together (compatible) or not (incompatible). Table 3 presents the results of AIDA, in which "I" indicates pairs of incompatible options and " $\mathrm{C}$ " compatible ones.

Finally, alternative solutions to the problem were assembled, by exhaustively combining compatible options across all decision areas; incompatible pairs are simply left out. Six strategies were presented for the DM evaluation in Phase 3, as presented in Table 4 .

It can be noted that every strategy has a focus point, also presented in Table 4, that naturally emerged when the modeler started matching the different options available. This focal point was used as reference for the DM, so he could quickly remember what every alternative stood for, although the complete table describing every alternative was also available on every screen of the final survey.

\subsection{Phase 3: Preference Modeling and Alternative Evaluation.} On every question of the fourth electronic survey, the DM was asked to evaluate all alternatives against one of the performance criteria previously defined. For that, the scale of the criterion's attribute was presented and the DM could place each alternative along that scale. This method, referred to in

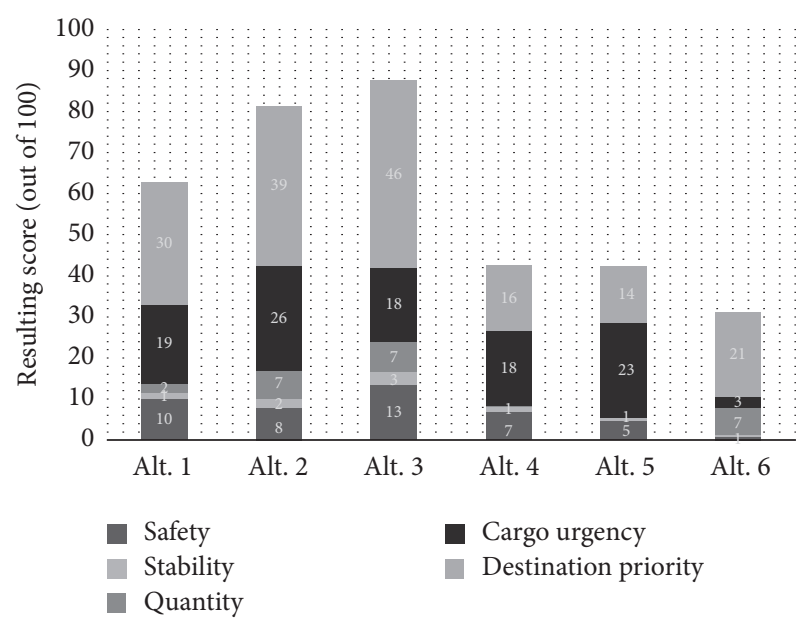

FIGURE 5: Weighted scores of each alternative.

the literature as direct evaluation, helps the DM visualize the difference between the alternative's performances directly on a scale, which is better than presenting attribute values [13]. As a result, a score value was assigned to every alternative, according to its position on the scale, that goes from 0 to 100 . Table 5 shows the resulting scores.

Criteria ranking was also done in the fourth survey. The DM was given the following instruction: "imagine a scenario where the current aid distribution is performing as badly as possible, which means that it is delivering the worse performance level possible on all the evaluation criteria, worth 0 on the previous scales. If you could improve the distribution in terms of only one criterion, raising its performance to the high end of the scale, which criterion would it be? Then, assuming all criteria but the one you already chose are still on the low end of their attribute scales, which is the next attribute you would choose to be at its highest performance level? Please repeat this process until all criteria are at their top levels." The first criterion selected is ranked number 1 , the second is number 2 , and so forth, resulting in the ranking presented in Table 6 . Later, the modeler used the ROC formula to calculate the relative weight of all the criteria, also shown in Table 6.

Finally, it was possible to obtain the general performance of each alternative by aggregating their partial results, as the weighted sum of their partial performances. Figure 5 illustrates the results obtained.

Each alternative is represented in Figure 5 by a column, with its height being the alternative's final score and its partial scores, measured against each criterion, represented in different shades along the column. It can be noted that the best strategy analyzed is the third, named "focus on the conditions of the destinations," with an overall performance of 87 points. The second alternative, "focus on type of load," comes in second with 78 points. Options 4 and 5 , which focus on managing requests according to the requesting organization, perform relatively close to the sixth option, which represents a FIFO strategy. Hence, it would be interesting to discard the final 3 alternatives and further explore the 
TABLE 4: Alternatives for the decision studied, formed by combining options from Table 2.

\begin{tabular}{|c|c|c|c|}
\hline$\#$ & $\begin{array}{c}\text { Alternative } \\
\text { Focus }\end{array}$ & Option combination & Description \\
\hline 1 & Response speed & $\mathrm{A}_{2}-\mathrm{B}_{1}-\mathrm{C}_{1}$ & $\begin{array}{l}\text { Load vehicles with cargo specified by cargo movement requests; } \\
\text { Select requests that can be fulfilled faster } \\
\text { Allow vehicles to travel independently (no need for convoys) }\end{array}$ \\
\hline 2 & Cargo type & $A_{3}-B_{2}-C_{1}$ & $\begin{array}{l}\text { Deliver one cargo type at a time, according to cargo priority } \\
\text { Select requests that contain high priority cargo, until reaching a min. SL } \\
\text { Allow vehicles to travel independently (no need for convoys) }\end{array}$ \\
\hline 3 & Conditions at destinations & $A_{1}-B_{3}-C_{2}$ & $\begin{array}{l}\text { Send a product mix with all cargo types, in quantities proportional to priorities } \\
\text { Select first the severely hit destinations that are still under a min. SL } \\
\text { Always travel in convoys }\end{array}$ \\
\hline 4 & Politics and cargo mix & $A_{1}-B_{4}-C_{2}$ & $\begin{array}{l}\text { Send a product mix with all cargo types, in quantities proportional to priorities } \\
\text { Select destinations according to power groups' interests until a min. SL is reached } \\
\text { Always travel in convoys }\end{array}$ \\
\hline 5 & Politics and cargo type & $\mathrm{A}_{3}-\mathrm{B}_{4}-\mathrm{C}_{1}$ & $\begin{array}{l}\text { Deliver one cargo type at a time, according to cargo priority } \\
\text { Select destinations according to power groups' interests until a min. SL is reached } \\
\text { Allow vehicles to travel independently (no need for convoys) }\end{array}$ \\
\hline 6 & Fast decision-making & $\mathrm{A}_{2}-\mathrm{B}_{5}-\mathrm{C}_{1}$ & $\begin{array}{l}\text { Load vehicles with cargo specified by cargo movement requests } \\
\text { Select requests according to their issue date, using a FIFO approach } \\
\text { Allow vehicles to travel independently (no need for convoys) }\end{array}$ \\
\hline
\end{tabular}

TABLE 5: Scores of each alternative (columns) on each criterion (lines), from 0 (worst performance possible) to 100 (best performance).

\begin{tabular}{|c|c|c|c|c|c|c|}
\hline Criterion & $\begin{array}{c}\text { Alt. } 1 \\
\text { (Speed) }\end{array}$ & $\begin{array}{c}\text { Alt. } 2 \\
\text { (Cargo type) }\end{array}$ & $\begin{array}{c}\text { Alt. } 3 \\
\text { (Destinations) }\end{array}$ & $\begin{array}{c}\text { Alt. } 4 \\
\text { (Politics + cargo mix) }\end{array}$ & $\begin{array}{c}\text { Alt. } 5 \\
\text { (Politics + cargo type) }\end{array}$ & $\begin{array}{l}\text { Alt. } 6 \\
\text { (FIFO) }\end{array}$ \\
\hline Safety & 65 & 50 & 85 & 45 & 30 & 5 \\
\hline Stability & 35 & 55 & 85 & 25 & 20 & 10 \\
\hline Quantity & 25 & 75 & 80 & 5 & 0 & 75 \\
\hline Cargo urgency & 75 & 100 & 70 & 70 & 90 & 10 \\
\hline Destination priority & 65 & 85 & 100 & 35 & 30 & 45 \\
\hline Total & 265 & 365 & 420 & 180 & 170 & 145 \\
\hline
\end{tabular}

TABLE 6: Rank position of each performance criterion and its resulting weight.

\begin{tabular}{lcc}
\hline Criterion & $\begin{array}{c}\text { Ranking } \\
\text { position }\end{array}$ & $\begin{array}{c}\text { Calculated weight } \\
\text { [Nondimensional] }\end{array}$ \\
\hline $\begin{array}{l}\text { Safety (of the cargo and the } \\
\text { workers) }\end{array}$ & 3 & 0,157 \\
$\begin{array}{l}\text { Stability among local } \\
\text { communities } \\
\begin{array}{l}\text { Quantity delivered, } \\
\text { proportionally to needs } \\
\text { Speed of urgent cargo delivery }\end{array}\end{array}$ & 5 & 0,040 \\
$\begin{array}{l}\text { Demand fulfillment at priority } \\
\text { locations }\end{array}$ & 1 & 0,090 \\
\hline
\end{tabular}

other strategies. In this study case, criteria weights did not modify the original alternative rank, but the performances of alternatives 2 and 3 became closer to each other. This may be a side effect of having strategies that the DM would not actually consider in a real problem, so a second round of evaluation considering new alternatives is recommended before making a final decision.

\section{Conclusions}

Elucidating the objectives behind humanitarian operations is important to support the challenging decisions faced by logistics teams in disaster aftermath. Drawing a distribution plan to transport relief items is an urgent, highly complex task, especially right after the disaster, when victims are very sensitive to delivery delays. Hence, having a strategy that expedites decision-making can impact positively the operation's overall performance. Moreover, when organizations act together, sharing limited resources to deliver relief items to the victims, primarily agreed upon guidelines could increase transparency of the decision-making process and avoid the use of flawed mind models.

An interesting aspect of the decision problem explored throughout this paper is the diversity of objectives that arise when dealing with humanitarian aid delivery. Conflicting objectives and the need to consider several stakeholders, as opposed to only focusing on the victims' needs, are challenges that need to be overcome when drawing distribution plans. Evaluating alternatives in terms of clear, explicitly stated objectives may help humanitarian actors justify their decisions to funding institutions, donors, and other powerful 
stakeholders that could otherwise interpret the same decisions badly. Besides, by using MCDA it is possible to come up with strategies that result in better outcomes, as judged by the DMs themselves.

Finally, this article illustrates the applicability of SMARTER, a Multi-Attribute Value Theory technique, to the humanitarian field. The work presented here shows SMARTER can be used with VFT to make objectives explicit to all stakeholders involved, helping the coordination team to make and justify decisions. Nonetheless, our contribution is not limited to the humanitarian logistics, but includes the documentation of an alternative generation method, which the MCDA literature still lacks, and presents a framework for applying MCDA when interactions with a Decision Maker are restricted. Although the methodology presented here revealed it is possible to enrich a brainstorming session using the literature, leading to the identification of goals that were not recalled by the DM himself, some published objectives were refuted by the DM, which may indicate an incompatibility between performance criteria used in OR models and those that are considered important by humanitarian actors. We hope our results give compelling arguments for humanitarian logisticians to invest in problem-structuring before building OR models.

\section{Conflicts of Interest}

The authors declare that there are no conflicts of interest regarding the publishing of this paper.

\section{Acknowledgments}

This work could be accomplished thanks to the financial support granted by CAPES (Coordination for the Improvement of Higher Level Personnel) and the DM who agreed to participate in this research.

\section{References}

[1] L. N. Van Wassenhove, "Humanitarian aid logistics: supply chain management in high gear," Journal of the Operational Research Society, vol. 57, no. 5, pp. 475-489, 2006.

[2] E. Gralla, Human and Modeling Approaches for Humanitarian Transportation Planning, Massachusetts Institute of Technology, 2012.

[3] L. N. Van Wassenhove and A. J. Pedraza Martinez, "Using OR to adapt supply chain management best practices to humanitarian logistics," International Transactions in Operational Research, vol. 19, no. 1-2, pp. 307-322, 2012.

[4] J. Holguín-Veras, N. Pérez, M. Jaller, L. N. Van Wassenhove, and F. Aros-Vera, "On the appropriate objective function for postdisaster humanitarian logistics models," Journal of Operations Management, vol. 31, no. 5, pp. 262-280, 2013.

[5] A. Leiras, I. de Brito, E. Queiroz Peres, T. Rejane Bertazzo, and $\mathrm{H}$. Tsugunobu Yoshida Yoshizaki, "Literature review of humanitarian logistics research: trends and challenges," Journal of Humanitarian Logistics and Supply Chain Management, vol. 4, no. 1, pp. 95-130, 2014.
[6] N. Altay and W. G. I. Green III, "OR/MS research in disaster operations management," European Journal of Operational Research, vol. 175, no. 1, pp. 475-493, 2006.

[7] L. E. De la Torre, I. S. Dolinskaya, and K. R. Smilowitz, "Disaster relief routing: Integrating research and practice," Socio-Economic Planning Sciences, vol. 46, no. 1, pp. 88-97, 2012.

[8] E. Gralla, J. Goentzel, and C. Fine, "Assessing trade-offs among multiple objectives for humanitarian aid delivery using expert preferences," Production Engineering Research and Development, vol. 23, no. 6, pp. 978-989, 2014.

[9] A. Davidson, Key performance indicators in humanitarian logistics, Massachusetts Institute of Technology, 2006.

[10] B. M. Beamon and B. Balcik, "Performance measurement in humanitarian relief chains," International Journal of Public Sector Management, vol. 21, no. 1, pp. 4-25, 2008.

[11] S. French, "Value-focused thinking: A path to creative decision making, Keeney, R. L., Cambridge, MA: Harvard University Press, 1992, ISBN 0-674-93197-1," Journal of Multi-Criteria Decision Analysis, vol. 2, no. 1, pp. 59-59, 1993.

[12] R. L. Keeney, "Building models of values," European Journal of Operational Research, vol. 37, no. 2, pp. 149-157, 1988.

[13] V. Belton and T. J. Stewart, Multiple Criteria Decision Analysis, Kluwer Academic Publishers, Norwell, Mass, USA, 1st edition, 2002.

[14] M. Marttunen, J. Lienert, and V. Belton, "Structuring problems for multi-criteria decision analysis in practice: a literature review of method combinations," European Journal of Operational Research, vol. 263, no. 1, pp. 1-17, 2017.

[15] L. A. Franco and G. Montibeller, "Problem structuring for multicriteria decision analysis interventions," in Wiley Encyclopedia of Operations Research and Management Science, J. Cochran, L. CoxJr, P. Keskinocak, J. Kharoufeh, and J. Smith, Eds., John Wiley Sons, Inc, New York, NY, USA, 2010.

[16] R. L. Keeney, "Value-focused thinking: Identifying decision opportunities and creating alternatives," European Journal of Operational Research, vol. 92, no. 3, pp. 537-549, 1996.

[17] G. S. Parnell, D. W. Hughes, R. C. Burk et al., "Invited ReviewSurvey of Value-Focused Thinking: Applications, Research Developments and Areas for Future Research," Journal of MultiCriteria Decision Analysis, vol. 20, no. 1-2, pp. 49-60, 2013.

[18] R. Gregory and R. L. Keeney, "Creating policy alternatives using stakeholder values," Management Science, vol. 40, no. 8, pp. 1035-1038, 1994.

[19] G. Montibeller and L. A. Franco, "Raising the bar: Strategic multi-criteria decision analysis," Journal of the Operational Research Society, vol. 62, no. 5, pp. 855-867, 2011.

[20] A. Trivedi and A. Singh, "Prioritizing emergency shelter areas using hybrid multi-criteria decision approach: A case study," Journal of Multi-Criteria Decision Analysis, vol. 24, no. 3-4, pp. 133-145, 2017.

[21] F. H. Barron and B. E. Barrett, "The efficacy of SMARTER - simple multi-attribute rating technique extended to ranking," Acta Psychologica, vol. 93, no. 1-3, pp. 23-36, 1996.

[22] V. J. Del Rio Vilas, A. Burgeño, G. Montibeller, A. Clavijo, M. A. Vigilato, and O. Cosivi, "Prioritization of capacities for the elimination of dog-mediated human rabies in the Americas: Building the framework," Pathogens and Global Health, vol. 107, no. 7, pp. 340-345, 2013.

[23] R. W. Curran, M. E. Bates, and H. M. Bell, "Multi-criteria decision analysis approach to site suitability of U.S. Department of Defense humanitarian assistance projects," in Proceedings 
of the Humanitarian Technology: Science, Systems and Global Impact 2014, HumTech2014, pp. 59-63, usa, May 2014.

[24] C. Çetinkaya, E. Özceylan, M. Erbaş, and M. Kabak, "GIS-based fuzzy MCDA approach for siting refugee camp: A case study for southeastern Turkey," International Journal of Disaster Risk Reduction, vol. 18, pp. 218-231, 2016.

[25] A. Trivedi and A. Singh, "A hybrid multi-objective decision model for emergency shelter location-relocation projects using fuzzy analytic hierarchy process and goal programming approach," International Journal of Project Management, vol. 35, no. 5, pp. 827-840, 2017.

[26] J. Wallenius, J. S. Dyer, P. C. Fishburn, R. E. Steuer, S. Zionts, and K. Deb, "Multiple criteria decision making, multi-attribute utility theory: recent accomplishments and what lies ahead," Management Science, vol. 54, no. 7, pp. 1336-1349, 2008.

[27] W. Edwards and F. H. Barron, "SMARTS and SMARTER: improved simple methods for multiattribute utility measurement," Organizational Behavior and Human Decision Processes, vol. 60, no. 3, pp. 306-325, 1994.

[28] R. A. Howard, "Decision analysis: practice and promise," Management Science, vol. 34, no. 6, pp. 679-695, 1988.

[29] A. Weas and M. Campbell, "Rediscovering the analysis of interconnected decision areas," AI EDAM Artificial Intelligence for Engineering Design, Analysis and Manufacturing, vol. 18, no. 3, pp. 227-243, 2004.

[30] Logistics Cluster, "Emergency Response Operation - Service Portfolio," Logistics Cluster, vol. 1, no. 3, 2012. 


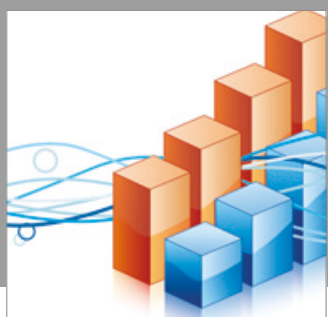

Advances in

Operations Research

vatersals

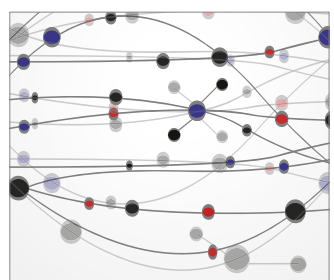

\section{The Scientific} World Journal
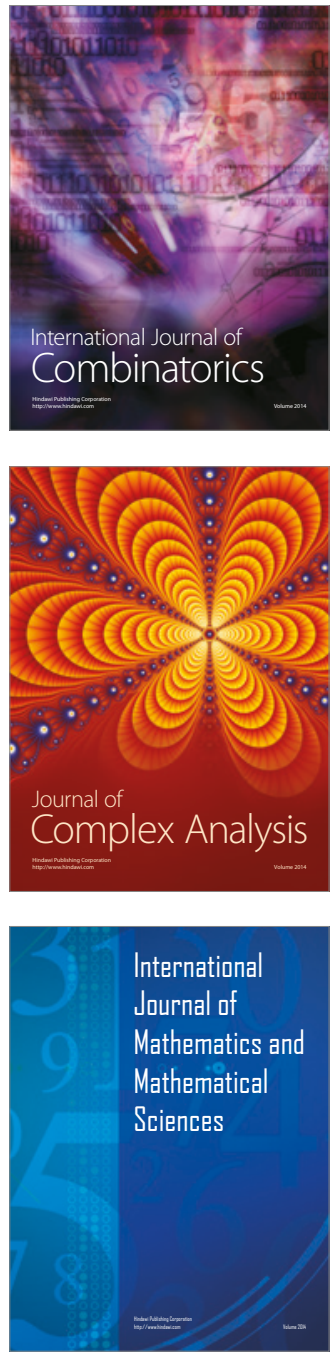
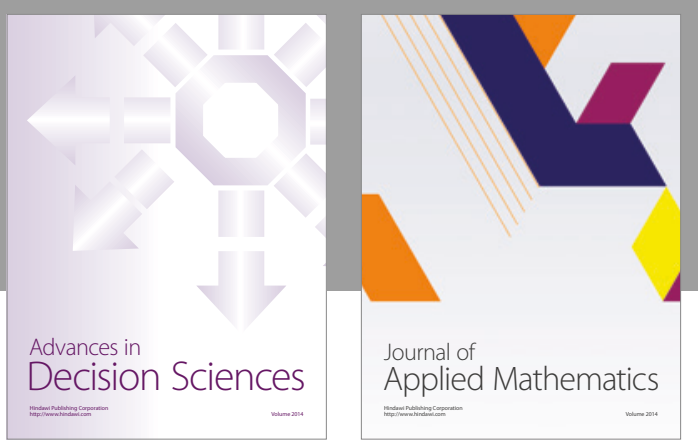

Algebra

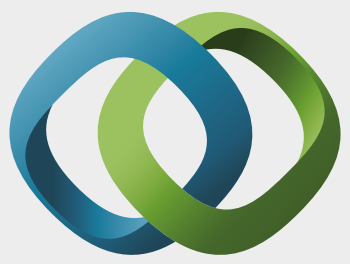

\section{Hindawi}

Submit your manuscripts at

https://www.hindawi.com
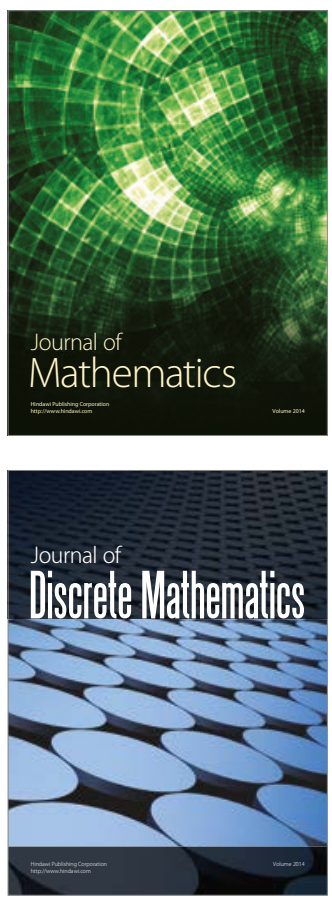

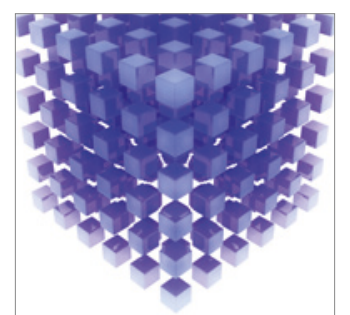

Mathematical Problems in Engineering
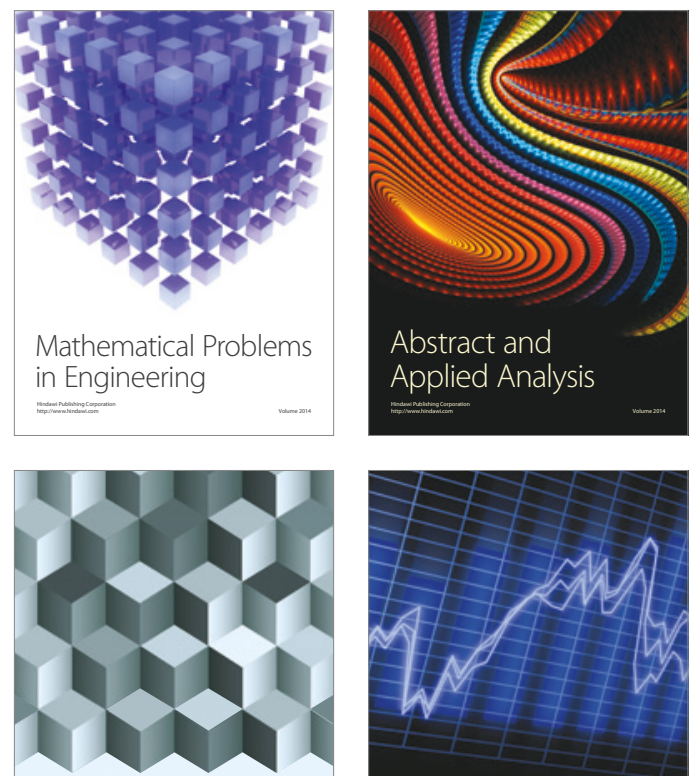

Journal of

Function Spaces

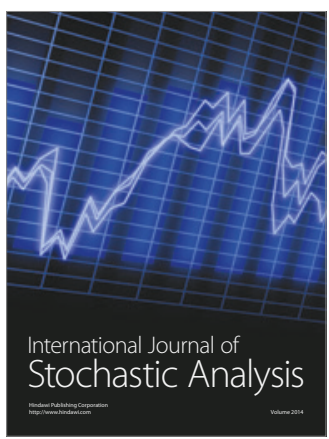

Probability and Statistics
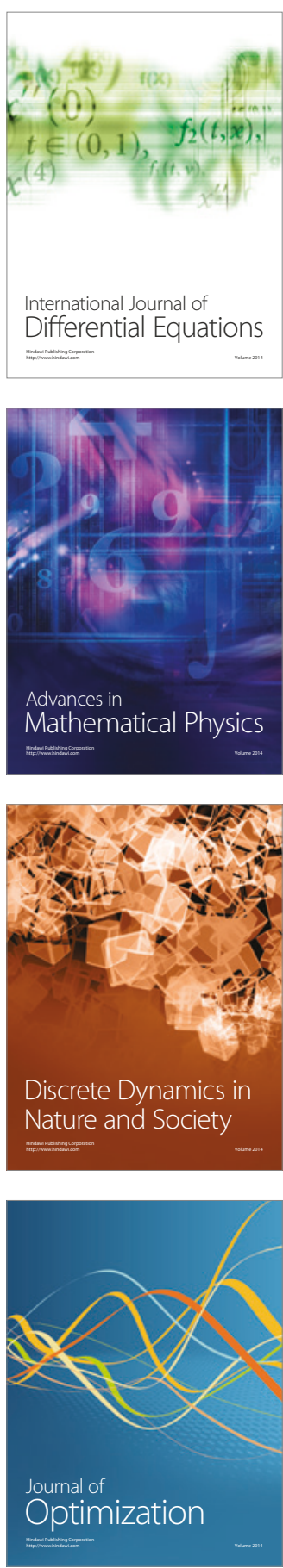